\title{
ПОВЫШЕНИЕ АДГЕЗИОННЫХ СВОЙСТВ КОММУТАЦИОННЫХ СЛОЁВ НА ПОЛУПРОВОДНИКОВЫХ ВЕТВЯХ $p$-ТИПА ТЕРМОЭЛЕКТРИЧЕСКИХ ГЕНЕРАТОРНЫХ БАТАРЕЙ
}

\author{
(C) 2018 Е. К. Белоногов ${ }^{1,2}$, В. А. Дыбов ${ }^{1}$, А. В. Костюченко ${ }^{1}$, С. Б. Кущев ${ }^{1}$, Д. В. Сериков ${ }^{1}$, \\ С. А. Солдатенко ${ }^{1}$ Е. Н. Федорова ${ }^{1}$, М. А. Погорелова ${ }^{1}$, А. О. Росляков ${ }^{1}$ \\ ${ }^{1}$ Воронежский государственный технический университет, Московский пр., 14, 394026 Воронеж, Россия \\ ${ }^{2}$ Воронежский государственный университет, Университетская пл., 1, 394018 Воронеж, Россия \\ e-mail:dybovvlad@gmail.com
}

Поступила в редакцию 03.11.2018

\begin{abstract}
Аннотация. Проведены сравнительные исследования фазового состава, морфологии, твердости и адгезии поверхности полупроводниковых термоэлектрических ветвей на основе твердого раствора $\mathrm{Bi}_{2} \mathrm{Te}_{3}-\mathrm{Sb}_{2} \mathrm{Te}_{3}$ р-типа проводимости, полученных методом горячего прессования, после модификации поверхности различными методами (механическая обработка (МП), импульсная фотонная обработка (ИФО), электрохимическая полировка (ЭХП)). Установлено, что МП упрочняет приповерхностный слой, повышает в 2 раза адгезию коммутационных барьерных слоев Мо-Ni. Последующие ЭХП повышает адгезию слоев Мо-Ni в 1.3 раза, а ИФО в 1.4 раза в сравнении с ветвями после МП.
\end{abstract}

Ключевые слова: термоэлектричество, теллурид висмута, модификация поверхности, барьерный слой, фазовый состав, твердость, адгезия.

DOI: https://doi.org/10.17308/kcmf.2018.20/629

\section{ВВЕДЕНИЕ}

Повышение эффективности термоэлектрических устройств является актуальной задачей альтернативной энергетики. Ее решение проводится в основном по двум направлениям: поиск новых термоэлектрических материалов и технологий их синтеза; разработка высоконадежных способов коммутационного соединения металл - полупроводник. Анализ работ за последнее десятилетие показал, что прогресс в решении этой задачи достигнут главным образом за счет первого направления. По второму направлению прогресс не столь очевиден. Сегодня основная технологическая проблема - недостаточная адгезионная прочность коммутационных соединений [1].

В качестве материалов ветвей термоэлектрических батарей, эффективно работающих в диапазоне умеренных температур от 373 до $523 \mathrm{~K}$, широкое распространение получили твердые растворы на основе теллурида висмута $\left(\mathrm{Bi}_{2} \mathrm{Te}_{3}\right)$, содержащие $\mathrm{Se}$ и $\mathrm{Sb}$, из которых могут быть созданы ветви как $n$-, так и $p$-типа [2]. Коммутация ветвей $n$ - и $p$-типа в термоэлектрическом элементе обычно осущест- вляется посредством проводящих шин $(\mathrm{Cu}, \mathrm{Ag}$ и $\mathrm{Al})$. Для спайки полупроводника с коммутационной шиной используются припои: $\mathrm{Sn}-\mathrm{Sb}, \mathrm{Sn}-\mathrm{Cu}$, $\mathrm{Sn}-\mathrm{Ag}, \mathrm{Sn}-\mathrm{Ag}-\mathrm{Bi}-\mathrm{Cu}, \mathrm{Sn}-\mathrm{Bi}$ и Bi-Sb. Чтобы предотвратить диффузию элементов припоя и проводящей шины в объем полупроводниковой ветви на ее поверхности создается различными способами тонкий проводящий барьерный слой (Ni, Mo, Ni-P, Co, $\mathrm{Ta}-\mathrm{Si}-\mathrm{N})$, характеризующийся низкой диффузионной подвижностью элементов, высокой адгезией к материалам припоя и ветвей $[3,4]$. Согласно требованиям к барьерной металлизации на термоэлектрических ветвях из теллурида висмута контакты должны иметь сопротивление не более $10^{-9} \mathrm{OM}^{\cdot} \mathrm{M}^{2}$ и прочность сцепления не менее $8 \mathrm{H} / \mathrm{MM}^{2}$ [5].

Как показали исследования, основной причиной деградации коммутационных контактов при эксплуатации термоэлементов на основе теллурида висмута являются низкие прочностные свойства этого материала и недостаточная адгезия барьерного слоя металлизации с поверхностью полупроводниковой ветви [6]. Несмотря на актуальность проблемы, ее решению уделяется сравнительно мало внимания. 
Как показано в отдельных работах, повысить адгезионную прочность возможно в результате обработки поверхности термоэлектрических ветвей различными методами [7-10]. Например, методы электрохимической полировки и ультразвуковой обработки позволяют увеличить адгезию металлизации до $19 \mathrm{H} / \mathrm{mм}^{2}$ и получить омические контакты с сопротивлением не более $10^{-10} \mathrm{Om} / \mathrm{Mм}^{2}$ на образцах твердых растворов халькогенидов висмута [7]. Однако создание гладкой и химически чистой поверхности полупроводниковых ветвей не является достаточным условием для надежных, прочных и воспроизводимых электрических характеристик контакта. Низкая шероховатость, полученная в работе [8], целесообразна для термоэлементов, используемых в микроэлектронике. Напротив, в ветвях для мощных силовых термогенераторных батарей развитая поверхность более эффективна, так как позволяет увеличить не только адгезию барьерного слоя, но и повысить добротность термоэлемента $[9,10]$.

Ранее авторами данной статьи были проведены исследование влияния различных способов подготовки поверхности ветвей на основе твердого раствора $\mathrm{Bi}_{2} \mathrm{Te}_{3}-\mathrm{Bi}_{2} \mathrm{Se}_{3} n$-типа на адгезию барьерной металлизации на основе молибдена и никеля $[11,12]$. Показано, что механическая полировка термоэлектрических ветвей упрочняет приповерхностный слой ветвей $n$-типа и повышает адгезию коммутационных барьерных слоев Mo-Ni более чем в 4 раза. Показана возможность модификации поверхности полупроводниковых термоэлектрических ветвей на основе твердого раствора $\mathrm{Bi}_{2} \mathrm{Te}_{3}-\mathrm{Bi}_{2} \mathrm{Se}_{3} n$-типа методом импульсной фотонной обработки. В работе [6] установлено, что характер разрушения в приконтактной области ветвей $n$ - и $p$-типа различен.

Поэтому целью данной работы стало исследование фазового состава, морфологии, твердости и адгезионных свойств поверхности полупроводниковых термоэлектрических ветвей $\mathrm{Bi}_{2} \mathrm{Te}_{3}-\mathrm{Sb}_{2} \mathrm{Te}_{3}$ (р-тип проводимости), полученных методом горячего прессования, после различных видов модификации поверхности.

\section{МЕТОДИКА ЭКСПЕРИМЕНТА И МЕТОДЫ ИССЛЕДОВАНИЯ}

Полупроводниковые кольца $p$-типа проводимости на основе твердого раствора $\mathrm{Bi}_{2} \mathrm{Te}_{3}-\mathrm{Sb}_{2} \mathrm{Te}_{3}$ получали путем холодного (удельное давление прессования $2.0 \pm 0.5 \mathrm{~T} / \mathrm{cm}^{2}$, время прессования $7.5 \pm 2.5$ с) и последующего горячего (удельное давление прессования $5.5 \pm 0.5 \mathrm{~T} / \mathrm{cm}^{2}$, температура $640 \pm 10 \mathrm{~K}$, время прессования 5 мин) изостатического прессования в вакууме $\left(10^{-2}\right.$ Па) порошков соответствующего состава и отжига полупроводниковых заготовок материала при $T=570$ К в течение 24 часов в вакууме $\left(10^{-1}\right.$ Па). Затем кольца подвергали резке алмазным диском на ветви.

Способы модификации полупроводниковых ветвей перед нанесением металлических пленок Мо и $\mathrm{Ni}$, применяемые в данной работе, приведены в табл. 1.

Первоначально все образцы подвергали механической обработке, которую проводили на диске с наждачной бумагой с карбидокремниевым абразивом различной зернистостью (от Р2000 до Р5000), до получения зеркальной поверхности. Затем, для отдельных образцов проводили импульсную фотонную обработку мощным излучением ксеноновых ламп (длина волны $0.2-$ 1.2 мкм) в атмосфере Ar при следующих режимах: двукратное облучение пакетом импульсов длительностью $10^{-2} \mathrm{c}$ за $0.8 \mathrm{c}$, что соответствовало энергии излучения, поступающей на образец

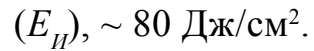

Для другой части образцов проводили ЭХП с целью удаления поврежденного механической обработкой поверхностного слоя полупроводника, а также очистки поверхности от оксидов и адсорбированных загрязнений. Для осуществления ЭХП, обрабатываемую ветвь в качестве анода между двумя графитовыми катодами помещали в ванну с электролитом. Для ЭХП использовали электролит состава: $\mathrm{KOH} \mathrm{-} 90$ г/л; $\mathrm{H}_{2} \mathrm{C}_{4} \mathrm{H}_{4} \mathrm{O}_{6}-65$ г/л, дистиллированная вода 845 г/л [13]. Процесс ЭХП проводили при комнатной температуре в течение 1 мин при плотности тока $120 \mathrm{MA} / \mathrm{cm}^{2}$ и напряжении $9 \mathrm{~B}$.

Таблица 1. Способы модифицирования поверхности полупроводниковых ветвей

[Table 1. Surface modification methods of the semiconductor branches]

\begin{tabular}{|c|c|}
\hline $\begin{array}{c}\text { Hoмер группы } \\
\text { [Group number] }\end{array}$ & $\begin{array}{c}\text { Обработка } \\
\text { [Treatment] }\end{array}$ \\
\hline 1 & МП [MP] \\
\hline 2 & МП+ИФО [MР+РРТ] \\
\hline 3 & МП+ЭХП [MР+ЕР] \\
\hline МП - механическая полировка; \\
[MР - mechanical polishing] \\
ИФО - импульсная фотонная обработка \\
[РРТ - pulse photon treatment]; \\
ЭХП - электрохимическая полировка \\
[ЕР - electrochemical polishing]. \\
\hline
\end{tabular}


Для удаления продуктов реакции после ЭХП ветви промывали в дистиллированной воде и проводили ультразвуковую обработку в изопропиловом спирте.

В качестве коммутационного слоя использовали никель, а в качестве барьерного - молибден. Послойное нанесение металлических слоев Мо и $\mathrm{Ni}$ на подготовленные поверхности полупроводниковых ветвей проводили методом магнетронного распыления соответствующих мишеней в среде $\operatorname{Ar}\left(4.2 \cdot 10^{-4}\right.$ мм. рт. ст.) на установке УВН-74М. Нагрев ветвей до 470 К осуществляли с помощью ИК ламп. Мощность магнетрона с Мо мишенью составляла 900 Вт, магнетрона с Ni мишенью 600 Вт соответственно. Скорость конденсации молибдена при этих параметрах составляла $3.3 \mathrm{Hм} / \mathrm{c}$, никеля $-1.8 \mathrm{Hм} / \mathrm{c}$.

Исследование фазового состава образцов производили методом рентгеновской дифрактометрии (Bruker D2 Phaser). Рельеф и шероховатость поверхности образцов исследовали методами атомно-силовой микроскопии (NT-MDT Solver P47). Твердость образцов исследовали методом измерительного наноиндентирования на нанотвердомере Nano Hardness Tester (CSM Instruments) с алмазным индентором Берковича. Максимальная величина нагрузки на индентор составляла $10.0 \mathrm{мH}$ и 200.0 мН. Скорость нагружения при индентировании составляла 15 и 300 мН/мин соответственно. Значения твердости по Мейру и модуля Юнга поверхностного слоя образцов определяли по методу Оливера и Фара согласно ГОСТ Р 8.748-2011. Данный блок обработки результатов входит в математический пакет программы «Indentation», прилагаемой к нанотвердомеру. Измерение адгезии покрытий к ветвям осуществляли методом испытаний на сдвиг согласно ГОСТ Р 52641-2006 на разрывной машине РПМ-10МГ4. Нагрузку осуществляли при постоянной скорости поперечного перемещения, равной 1.0 мм/мин. Вычисление адгезии покрытий производили по формуле $R=P / F$, где $P$ - максимальное значение нагрузки, $F$ - площадь клеевого соединения.

\section{РЕЗУЛЬТАТЫ И ОБСУЖДЕНИЕ}

\section{Фазовый состав, морфология и твердость} поверхности полупроводниковых ветвей

Фазовый состав. На рис. 1 представлены рентгеновские дифрактограммы, характеризующие фазовый состав поверхностных слоев полупроводниковых ветвей до и после модификации поверхности разными способами.
На дифрактограмме исходной ветви (кривая 1) присутствуют отражения, соответствующие ромбоэдрической решетке $\mathrm{Bi}_{0.4} \mathrm{Sb}_{1.6} \mathrm{Te}_{3}(R \overline{3} m)$ [14]. Относительно высокая интенсивность отражений (006) $\mathrm{Bi}_{0.4} \mathrm{Sb}_{1.6} \mathrm{Te}_{3}$ свидетельствует о наличии преимущественной текстуры с осью зоны $<0001>$. Кроме того, наблюдаются отражения, соответствующие гексагональной решетке Те. Присутствие отражений Те может быть обусловлено массопереносом Те в результате сублимации и последующей конденсации его на поверхность образцов в процессе термического отжига в вакууме.

На дифрактограмме ветвей после модификации поверхности методами МП и МП+ЭХП наблюдаются отражения, соответствующие только решетке $\mathrm{Bi}_{0.4} \mathrm{Sb}_{1.6} \mathrm{Te}_{3}$. Отсутствие пиков, соответствующих решетке Те, свидетельствует об удалении с поверхности включений данной фазы в указанных процессах. Как видно из рис. 1, для образцов, прошедших МП поверхности ветвей, наблюдается уширение дифракционных пиков и уменьшение интенсивности пика (006). Данные изменения свидетельствует о том, что в приповерхностном слое происходит уменьшение размера зерен и появление зерен произвольной ориентации. Уширению дифракционных максимумов также могут способствовать напряжения, возникающие в приповерхностных слоях в результате их деформации.

Для ветвей, прошедших МП+ИФО, происходит незначительное уменьшение ширины пиков и появление пиков соответствующих кристаллической фазы Те. Данные изменения связаны с процессами рекристаллизации, происходящими на поверхности ветвей (при ИФО на поверхности ветвей создаются температуры $800 \mathrm{~K}$ ). Выделение фазы Те в приповерхностной области вследствие термообработки и ИФО обусловлено температурной зависимостью ширины области гомогенности соединения $\mathrm{Bi}_{2} \mathrm{Te}_{3}$ на диаграмме состояния [15]. В диапазоне температур от 670 до 858 К ширина области гомогенности монотонно сужается, поэтому при изотермической выдержке в этом диапазоне исходного гомогенного состава с избытком теллура происходит его выделение в виде отдельной фазы, как правило, на границах зерен $\mathrm{Bi}_{2} \mathrm{Te}_{3}$. При медленном охлаждении полупроводниковых ветвей сегрегированный Те успевает вернуться в раствор, а при относительно быстром охлаждении, реализуемом в приповерхностной области, включения теллура не успевают растворяться (замороженное состояние). 


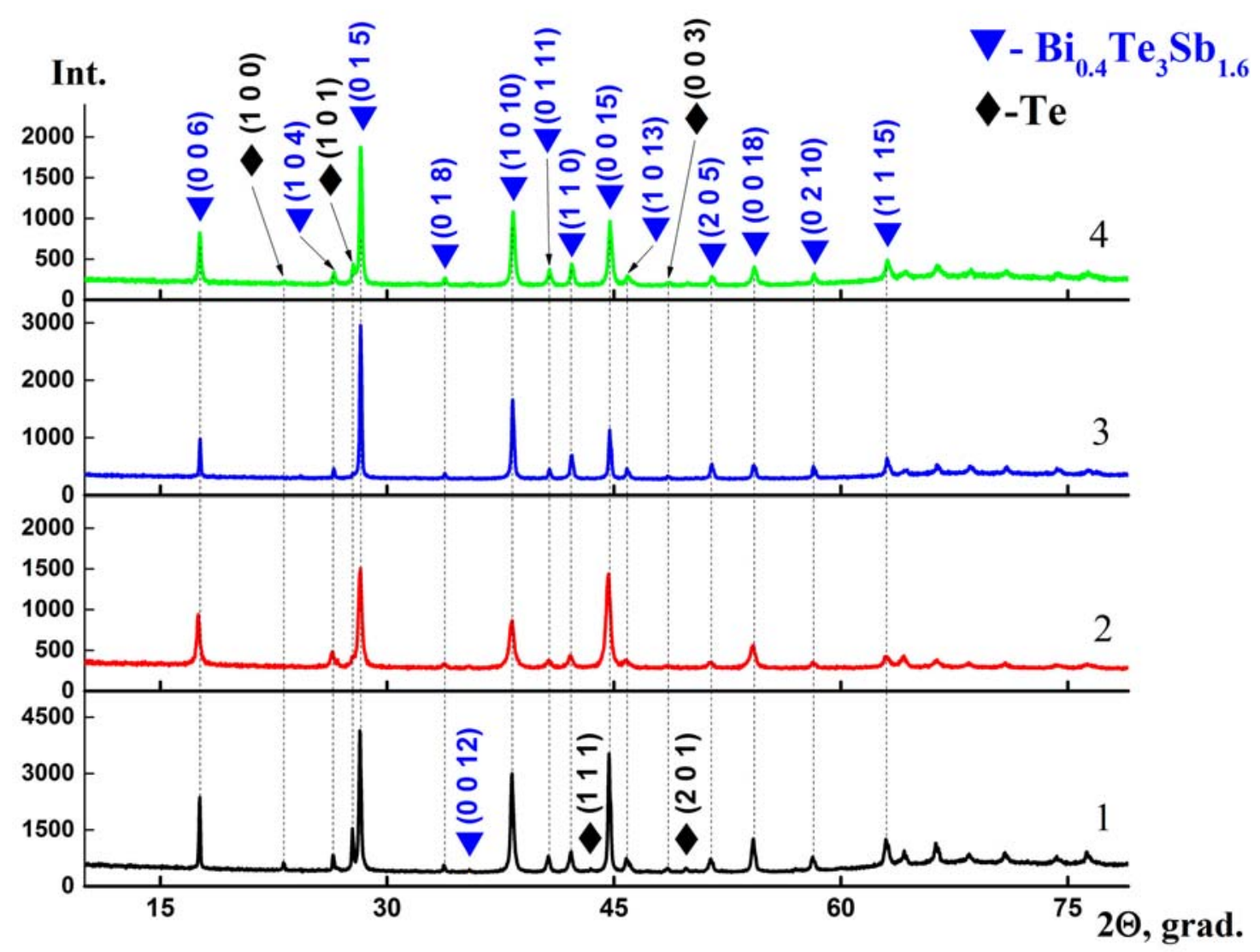

Рис. 1. Рентгеновские дифрактограммы ветвей на основе твердого раствора $\mathrm{Bi}_{2} \mathrm{Te}_{3}-\mathrm{Sb}_{2} \mathrm{Te}_{3}$ (р-тип) до (кривая 1) и после МП (кривая 2), МП+ЭХП (кривая 3) и МП+ИФО (кривая 4)

[Fig. 1. X-ray diffractograms of branches based on solid solution $\mathrm{Bi}_{2} \mathrm{Te}_{3}-\mathrm{Sb}_{2} \mathrm{Te}_{3}$ (p-type) before (curve 1) and after $\mathrm{MP}$ (curve 2), $\mathrm{MP}+\mathrm{EP}$ (curve 3) and $\mathrm{MP}+\mathrm{PPT}$ (curve 4)]

Морфология поверхности. На рис. 2 приведены АСМ сканы и гистограммы распределения высот для исходных образцов и после разных вариантов обработки. Данные анализа приведены в табл. 2.

По данным АСМ исходная поверхность образцов представлена неоднородностями рельефа размером до 1 мкм в латеральном направлении и до 0.5 мкм по высоте (рис. 2a).

Рельеф поверхности обусловлен конденсацией Те в процессе отжига ветвей, а также пластической деформацией материала (экструзией) в прессформе. Кроме того, рельеф поверхности ветвей наследует неровности (шероховатость) пресс-формы. Все конденсационные и деформационные изменения шероховатости поверхности приводят к ухудшению адгезионных свойств поверхности твердого раствора.

После механической полировки поверхность ветвей $\mathrm{Bi}_{2} \mathrm{Te}_{3}-\mathrm{Sb}_{2} \mathrm{Te}_{3}$ имеет неоднородный рельеф (см. рис. 2c), перепад высоты до 0.4 мкм. Асим-
Таблица 2. Параметры рельефа поверхности полупроводниковых ветвей теллурида висмута до и после обработок

[Table 2. Surface relief parameters of the semiconductor branches of bismuth telluride before and after treatments]

\begin{tabular}{|c|c|c|}
\hline $\begin{array}{c}\text { Обработка } \\
\text { Поверхности } \\
\text { [Surface treat- } \\
\text { ment] }\end{array}$ & $\begin{array}{c}\text { Перепад } \\
\text { высоты, нм } \\
\text { [Height } \\
\text { difference, } \mathrm{nm}]\end{array}$ & $\begin{array}{c}\text { Шероховатость } \\
\text { на площади } \\
0.01 \mathrm{MM}^{2}, \mathrm{HM} \\
\text { [Roughness } \\
\text { on the area } \\
\left.\text { of } 0.01 \mathrm{~mm}^{2}, \mathrm{~nm}\right]\end{array}$ \\
\hline $\begin{array}{c}\text { Исходный } \\
\text { образец } \\
\text { [sourсе sample] }\end{array}$ & 1400 & 120 \\
\hline $\begin{array}{c}\text { МП } \\
\text { [МР] }\end{array}$ & 450 & 35 \\
\hline $\begin{array}{c}\text { МП+ЭХП } \\
\text { [МР+ЕР] }\end{array}$ & 400 & 30 \\
\hline $\begin{array}{c}\text { МП+ИФО } \\
\text { [МР+РРТ] }\end{array}$ & 150 & 25 \\
\hline
\end{tabular}



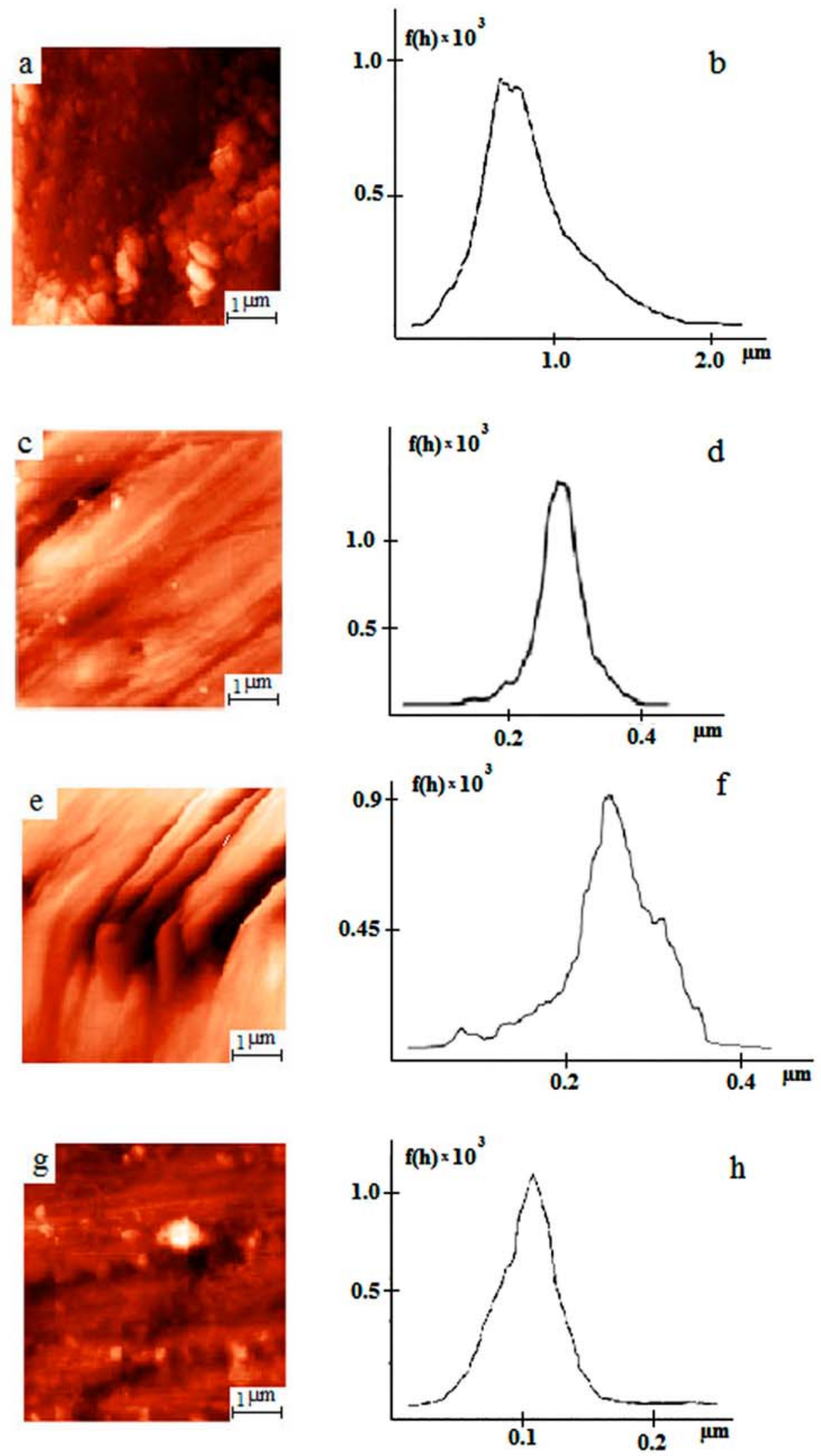

Рис. 2. АСМ сканы и гистограммы распределения высоты поверхности исходных полупроводниковых ветвей $(a$, $b)$ и прошедших МП $(c, d)$, МП+ЭХП $(e, f)$ и МП+ИФО $(g, h)$

[Fig. 2. AFM scans and histograms of surface height distribution semiconductor branches before $(a, b)$ and past MP $(c$, $d), \operatorname{MP}+\mathrm{EP}(e, f)$ and $\mathrm{MP}+\mathrm{PPT}(g, h)]$ 
метрия гистограммы указывает на доминирование впадин над выступами, следовательно, полировка успешно устраняет выступы материала, но микротрещины и впадины не ликвидирует. Артефактами механической полировки служат царапины, а также дисперсные частицы на поверхности ветви. На АСМ скане (рис. 2e) поверхности образцов после ЭХП выявлены протяженные углубления с перепадом высоты более 0.5 мкм. При этом характер выступов и углублений непрямолинейный, характерный для электрохимического травления, отличающегося селективной скоростью по поверхности образца. Следы механической полировки отсутствуют. Асимметрия гистограммы распределения высоты рельефа указывает на преобладание протяженных выступов над остальными дефектами поверхности.

В результате ИФО механически полированных ветвей (рис. $2 g$ ) происходит формирование рельефа, содержащего дефекты в виде неоднородностей сферической формы, возможная природа появления которых - рекристаллизация кристаллитов в приповерхностном слое и конденсация теллура в процессе ИФО.

Механические свойства. В табл. 3 представлены величины твердости $(H)$ и модуля упругости $(E)$ приповерхностного слоя полупроводниковых ветвей, прошедших различные виды обработки.

Известно, что твердость высокодисперсных покрытий из твердых растворов на основе теллурида висмута до 2.5 раз выше твердости монокристаллов соответствующего состава [16]. Модуль Юнга в крупнозеренном (размер зерен $~ 20$ мкм) теллу-

Таблица 3. Твердость и модуль упругости приповерхностного слоя полупроводниковой ветви, прошедшей различные виды обработки

[Table 3. Hardness and elastic modulus of the surface layer of a semiconductor branch that have passed various processing]

\begin{tabular}{|c|c|c|c|c|}
\hline $\begin{array}{c}F, \mathrm{мH} \\
{[F, \mathrm{mN}]}\end{array}$ & \multicolumn{2}{|c|}{10} & \multicolumn{2}{c|}{200} \\
\hline & $\begin{array}{c}H, \text { ГПа } \\
{[H, \mathrm{GPa}]}\end{array}$ & $\begin{array}{c}E, \text { ГПа } \\
{[E, \mathrm{GPa}]}\end{array}$ & $\begin{array}{c}H, \text { ГПа } \\
{[H, \mathrm{GPa}]}\end{array}$ & $\begin{array}{c}E, \text { ГПа } \\
{[E, \mathrm{GPa}]}\end{array}$ \\
\hline $\begin{array}{c}\text { Без обработки } \\
\text { [Without treatment }]\end{array}$ & 1.3 & 33.5 & 1.0 & 31.2 \\
\hline $\begin{array}{c}\text { МП } \\
{[\mathrm{MР]}}\end{array}$ & 1.5 & 36.8 & 0.8 & 29.7 \\
\hline $\begin{array}{c}\text { МП+ЭХП } \\
{[\text { МР+ЕР] }}\end{array}$ & 1.0 & 28.6 & 0.7 & 25.9 \\
\hline $\begin{array}{c}\text { МП+ИФО } \\
{[\text { МР+РРТ] }}\end{array}$ & 1.1 & 31.8 & 1.0 & 29.2 \\
\hline
\end{tabular}

риде висмута с одноосной текстурой [0001] минимален вдоль направления [0001] и составляет около 32 ГПа; а при высокой дисперсности зеренной структуры (средний размер зерен около 0.2 мкм) и произвольной ориентации зерен модуль Юнга теллурида висмута составляет около 48 ГПа [17].

Как следует из табл. 3, в результате механической полировки наблюдается возрастание твердости и модуля Юнга приповерхностного слоя ветвей при нагрузке 10 Н и их снижение при нагрузке 200 мН. Наблюдаемый результат можно связать с удалением в процессе механической полировки нарушенного слоя в приповерхностной области исходных ветвей, который отличается от внутренних областей, как химическим составом, так и субструктурой. Вместо удаленного слоя формируется относительно тонкий деформированный слой, имеющий дисперсную зёренную структуру. Полученные при малой нагрузке на индентор (10 мН) величины $H$ и $E$ характеризуют только приповерхностный слой, а при нагрузке 200 мН в случае полированной ветви вклад в величины $H$ и $E$ вносят внутренние слои с крупнозёренной структурой.

ЭХП приводит к удалению деформированного приповерхностного слоя, поэтому наблюдаемые при обеих нагрузках величины $H$ и $E$ отражают упругие свойства слоев ветвей, состоящих из микрозерен внутренних слоев материала.

ИФО механически полированных ветвей приводит к рекристаллизации и формированию приповерхностных слоев с произвольной ориентацией зерен относительно большой толщины по сравнению с глубиной проникновения индентора. Следствием этого являются близкие значения $H$ для обеих нагрузок индентирования. Снижение $H$ и $E$ при ИФО по сравнению с механически полированными ветвями может быть связано с формированием закрытой пористости в объеме рекристаллизованного слоя.

\section{Адгезионные свойства приповерхностного слоя ветвей}

Исследование адгезионных свойств полупроводниковых ветвей проводили на образцах с нанесенными металлическими слоями на боковые поверхности. В результате изостатического прессования крупные кристаллиты $\mathrm{Bi}_{0.4} \mathrm{Sb}_{1.6} \mathrm{Te}_{3}$, как правило, расположены так, что их плоскости спайности составляют небольшой угол с плоскостью поверхности образца.

В гетероструктурах полупроводник-металл (Mo, Ni), у которых модифицирование поверхнос- 
ти ветвей осуществляли МП или МП+ЭХП, методом рентгеновской дифрактометрии были выявлены три кристаллические фазы: $\mathrm{Mo}, \mathrm{Ni}$ и $\mathrm{Bi}_{0.4} \mathrm{Sb}_{1.6} \mathrm{Te}_{3}$, а при МП+ИФО - четыре: $\mathrm{Mo}, \mathrm{Ni}, \mathrm{Bi}_{0.4} \mathrm{Sb}_{1.6} \mathrm{Te}_{3}$ и Те. Полученные данные свидетельствуют о том, что при конденсации металлических слоев на поверхность полупроводниковой ветви на межфазной границе полупроводник-металл химического взаимодействия компонентов с образованием дополнительных кристаллических фаз не происходит.

После испытаний на сдвиг у поверхности отрыва на ветви присутствует только фаза с решеткой $\mathrm{Bi}_{0.4} \mathrm{Sb}_{1.6} \mathrm{Te}_{3}$, что свидетельствует о разрушении гетероструктуры по межфазной границе полупроводник-металл (адгезионное разрушение) или по объему полупроводника (когезионное разрушение). Исследование поверхности слоев Мо показало, что наряду с участками чистого металла присутствуют и участки с фазой $\mathrm{Bi}_{0.4} \mathrm{Sb}_{1.6} \mathrm{Te}_{3}$, что говорит о смешанном механизме разрушения гетероструктуры.

Данные о величине адгезии покрытий и характере разрушения гетероструктур полупроводниковая ветвь - металлические слои, установленные по результатам СЗМ поверхности отрыва со стороны покрытия, представлены в табл. 4.

Для покрытий, полученных на немодифицированной поверхности ветвей, величина адгезии минимальная и составляет 1.2-2.1 МПа. Это может быть обусловлено высокой дефектностью (трещины, поры) приповерхностного слоя полупроводниковой ветви.
Как видно из табл. 4, МП ветвей $p$-типа повышает адгезию коммутационных барьерных слоев Mo-Ni в 2 раза по сравнению с адгезией слоев Mo-Ni на поверхности необработанных ветвей. Очевидно, это связано с одной стороны с уменьшением объемных дефектов исходной поверхности и, как показано выше, упрочнением приповерхностного слоя.

Низкую величину адгезии 1.2 МПа после МП+ЭПХ наблюдали только на образцах, у которых МП удаляли поверхностный слой малой толщины (до 0.1 мм); на поверхности ветвей оставался текстурированный слой с крупными зернами, у которых плоскости спайности расположены параллельно боковой поверхности ветви. В этом случае разрушение происходило по объему полупроводника по плоскостям спайности, то есть по когезионному механизму. Повышение адгезии покрытий на ветвях после ЭХП наблюдается в тех случаях, когда в результате МП удаляли поверхностный слой ветви относительно большой толщины (0.1-0.2 мм). В этом случае текстурированный слой боковой поверхности практически удалялся, и разрушение происходило по объему полупроводника и по межфазной границе полупроводник-металл.

Величина адгезии 2.3 МПа для ветвей, прошедших ИФО, относится к однократной ИФО. Двукратная ИФО, выполняемая после механической полировки, приводит к повышению адгезии до 3.9 МПа. В обоих случаях после ИФО механизм разрушения происходил по объему полупроводника и по межфазной границе полупроводник-металл.

Таблица 4. Величины адгезии покрытий и характер разрушения гетероструктур полупроводниковая ветвь - металлические слои

[Table 4. Adhesion values of coatings and the nature of the destruction of heterostructures semiconductor branch - metal layers]

\begin{tabular}{|c|c|c|}
\hline & $\begin{array}{l}R_{\text {сдвиг }}, \mathrm{MПа} \\
{\left[R_{\text {shift }}, \mathrm{MPa}\right]}\end{array}$ & $\begin{array}{l}\text { Характер разрушения } \\
\text { [Nature of destruction] }\end{array}$ \\
\hline $\begin{array}{c}\text { Без обработки } \\
\text { [Without treatment] }\end{array}$ & $1.2-2.1$ & $\begin{array}{l}\text { когезионный: по объему полупроводника } \\
\text { [cohesive: by semiconductor volume] }\end{array}$ \\
\hline $\begin{array}{l}\mathrm{M \Pi} \\
{[\mathrm{MP}]}\end{array}$ & $2.3-2.7$ & $\begin{array}{l}\text { смешанный: по объему полупроводника и по межфазной границе полупро- } \\
\text { водник-металл } \\
\text { [mixed: by semiconductor volume and semiconductor-metal interface] }\end{array}$ \\
\hline $\begin{array}{l}\mathrm{M \Pi +ЭХП} \\
{[\mathrm{MP}+\mathrm{EP}]}\end{array}$ & $1.2-3.7$ & $\begin{array}{l}\text { 1.2 МПа - когезионный: по объему полупроводника по слоям спайности; } \\
3.7 \mathrm{MПа} \mathrm{-} \mathrm{смешанный:} \mathrm{по} \mathrm{объему} \mathrm{полупроводника} \mathrm{и} \mathrm{по} \mathrm{межфазной} \mathrm{границе} \\
\text { полупроводник-металл } \\
\text { [1.2 MPa - cohesive: by the volume of the semiconductor in the layers of cleavage; } \\
\text { 3.7 MPa - mixed: by semiconductor volume and semiconductor-metal interface] }\end{array}$ \\
\hline 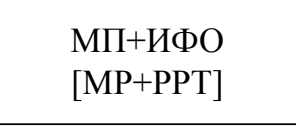 & $2.3-3.9$ & $\begin{array}{l}\text { смешанный: по объему полупроводника и по межфазной границе полупро- } \\
\text { водник-металл } \\
\text { [mixed: by semiconductor volume and semiconductor - metal interface] }\end{array}$ \\
\hline
\end{tabular}




\section{ВЫВОДЫ}

Установлено, что подготовка поверхности термоэлектрических ветвей на основе твердого раствора $\mathrm{Bi}_{2} \mathrm{Te}_{3}-\mathrm{Sb}_{2} \mathrm{Te}_{3} p$-типа методом механической полировки термоэлектрических ветвей $p$-типа упрочняет приповерхностный слой твердого раствоpa $\mathrm{Bi}_{2} \mathrm{Te}_{3}-\mathrm{Sb}_{2} \mathrm{Te}_{3}$, а также повышает адгезию коммутационных барьерных слоев Mo-Ni в 2 раза по сравнению с адгезией слоев Mo-Ni на поверхности необработанных ветвей. Последующая электрохимическая полировка повышает адгезию слоев Mo-Ni в 1.3 раза, а импульсная фотонная обработка в 1.4 раза по сравнению с механически полированными ветвями.

Показано, что энергетическое воздействие ИФО стимулирует локальную рекристаллизацию дефектного слоя у поверхности полупроводниковых ветвей на глубине 100-200 нм и увеличивает твердость приповерхностных слоев твердого раствора $\mathrm{Bi}_{2} \mathrm{Te}_{3}-\mathrm{Sb}_{2} \mathrm{Te}_{3}$ в 1.2 раза.

Работа выполнена с использованием научного оборудования Центра коллективного пользования им. проф. Ю. М. Борисова ВГТУ, Центрально-Черноземного коллективного центра анализа структуры, элементного и химического состава материалов ВГТУ и при финансовой поддержке Министерства образования и науки Российской Федерации в рамках постановления Правительства Российской Федерации от 9 апреля 2010z. №218 (Договор № 03.G25.31.0246).

\section{СПИСОК ЛИТЕРАТУРЫ}

1. Освенский В. Б., Каратаев В. В., Малькова Н. В. // Известия высших учебных заведений. Материалы электронной техники, 2002, с. 70-73.

2. Xie W., Tang X., Yan Y., et al. // Applied Physics Letters, 2009, vol. 94, № 10, p. 102111. DOI: https://doi. org/10.1063/1.3097026

3. Brostow W. Datashvili T., Hagg Lobland H. E., et al. // J. Mater. Res., 2012, vol. 27, № 22, pp. 2931-2936. DOI: https://doi.org/10.1557/jmr.2012.335

4. Громов Д. Г., Штерн Ю. И., Рогачев М. С. и др. // Неорганические материаль, 2016, т. 52, № 11, с. 1206-
1210. DOI: https://doi.org/10.7868/S0002337X16110038

5. Stern Yu. I., Shtern M. Yu., Sherchenkov A. A. // Russ. Microelectron., 2012, vol. 41, № 7, pp. 393-399. DOI: https://doi.org/10.1134/s1063739712070098

6. Yang N. Y. C., Morales, A. M. Morales Metallurgy, Thermal Stability, and Failure Mode of the Commercial Bi-Te-based Thermoelectric Modules. Sandia National Laboratories Albuquerque, New Mexico 87185 and Livermore, California 94550, 2009, p. 60. DOI: https://doi. org/10.2172/957291

7. Shtern, Y. I., Mironov R. E., Shtern M. Y., Sherchenkov A. A. and Rogachev M. S. // Acta Physica Polonica A, 2016, vol. 129, № 4, pp. 785-787. DOI: https://doi. org/10.12693/aphyspola.129.785

8. Feng H.-P., Yu B., Chen Sh., et al. // Electrochimica Acta, 2011, vol. 56, pp. 3079-3084. DOI: https://doi. org/10.1016/j.electacta.2010.12.008

9. Симкин А. В., Бирюков А. В., Репников Н. И., Иванов О. Н. // Термоэлектричество, 2012, № 2, с. 7682.

10. Марченко О. В., Кашин А. П., Лозбин В. И. Методы расчета термоэлектрических генераторов. Сибирская издательская фирма «Наука» РАН, 1995, c. 222 .

11. Белоногов Е. К., Дыбов В. А., Костюченко А. В. и др. // Вестник ВГТУ, 2017, т. 13, № 6, с. 110-116.

12. Белоногов Е. К., Дыбов В. А., Костюченко А. В. // Конденсированные среды и межфазные гранищы. 2017. т. 19, № 4, с. 479-488. DOI: https://doi. org $/ 10.17308 / \mathrm{kcmf} .2017 .19 / 226$

13. Tewari K. C., Gandotra V. K., Padmavati M. V. G., Singh A., Vedeshwar A. G. // Materials Chemistry and Physics, 2001, vol. 72, pp. 72-76. DOI: https://doi. org/10.1016/s0254-0584(01)00312-1

14. Powder Diffraction File. Alphabetical Index Inorganic Compounds. JCPDS, Pennsylvania 19081, U.S.A., 1977, p. 17.

15. Гольцман Б. М., Кудинов В. А., Смирнов И. А. Полупроводниковые термоэлектрические материаль на основе $B i_{2} T e_{3}$. Изд. -во «Наука», 1972, 161 с.

16. Tasi C.-H., Tseng Y.-C., Jian S.-R., et al. // Journal of Alloys and Compounds, 2015, vol. 619, pp. 834-838. DOI: https://doi.org/10.1016/j.jallcom.2014.09.028

17. Santamarнa J. A., Alkorta J., Sevillano J. G. // J. Mater. Res., 2015, vol. 30, № 17, pp. 2593-2604. DOI: https://doi.org/10.1557/jmr.2015.170 


\title{
INCREASE IN THE ADHESIVE PROPERTIES OF COMMUTATION LAYERS ON SEMICONDUCTOR $p$-TYPE BRANCHES OF THERMOELECTRIC GENERATOR BATTERIES
}

\author{
(C) 2018 E. K. Belonogov ${ }^{1,2}$, V. A. Dybov ${ }^{1}$, A. V. Kostyuchenko ${ }^{1}$, S. B. Kuschev ${ }^{1}$, D. V. Serikov ${ }^{1}$, \\ S. A. Soldatenko ${ }^{1}$, E. N. Fedorova ${ }^{1}$, M. A. Pogorelova ${ }^{1}$, A. O. Roslyakov ${ }^{1}$ \\ ${ }^{1}$ Voronezh State Technical University, 14, Moscow ave., 394026 Voronezh, Russia \\ ${ }^{2}$ Voronezh State University, 1, Universitetskaya pl., 394018 Voronezh, Russia \\ e-mail:dybovvlad@gmail.com \\ Received 06.11.2018
}

\begin{abstract}
Existing studies demonstrate that the main cause of the degradation of switching contacts during the operation of thermoelements based on bismuth telluride are the low strength properties of this material and the insufficient adhesion of the barrier metallization layer to the surface of the semiconductor branch.

The objective of this paper is to study the phase composition, morphology, hardness and adhesive properties of the surface of the semiconductor thermoelectric branches $\mathrm{Bi}_{2} \mathrm{Te}_{3}-\mathrm{Sb}_{2} \mathrm{Te}_{3}$ (p-type conductivity) obtained by hot pressing, after various types of surface modification.

$P$-type semiconductor branches based on $\mathrm{Bi}_{2} \mathrm{Te}_{3}-\mathrm{Sb}_{2} \mathrm{Te}_{3}$ solid solution were obtained by cold and subsequent hot isostatic pressing in vacuum $\left(10^{-2} \mathrm{~Pa}\right)$ of respective powders and annealing semiconductor material blanks at $T=570 \mathrm{~K}$ for 24 hours in vacuum $\left(10^{-1} \mathrm{~Pa}\right)$. Surface modification of semiconductor branches was carried out by mechanical polishing and subsequent electrochemical polishing or pulsed photon treatment with incoherent light. Mechanical polishing was performed on a carbide-silicon abrasive disc with different grain sizes (from P2000 to P5000), to obtain a mirror surface.

Pulsed photon treatment was performed by means of the radiation of xenon lamps (wavelength $0.2-1.2 \mu \mathrm{m}$ ) in an Ar atmosphere under the following conditions: double irradiation with a set of pulses with a duration of $10^{-2} \mathrm{~s}$ in $0.8 \mathrm{~s}$, which corresponds to the radiation energy reaching the sample (EP), $\sim 80 \mathrm{~J} / \mathrm{cm}^{2}$.

Electrochemical polishing was carried out in the following electrolyte composition: $\mathrm{KOH}-90 \mathrm{~g} / \mathrm{l}$; $\mathrm{H}_{2} \mathrm{C}_{4} \mathrm{H}_{4} \mathrm{O}_{6}-65 \mathrm{~g} / \mathrm{l}$, distilled water $845 \mathrm{~g} / \mathrm{l}$.

Nickel was used as the switching layer, and molybdenum was used as the barrier layer. The layered deposition of metallic layers (Mo and $\mathrm{Ni}$ ) onto the prepared surfaces of semiconductor branches was applied by magnetron sputtering of the corresponding targets in Ar.

The phase analyses were performed by X-ray diffractometry (Bruker D2 Phaser). The relief and surface roughness of the samples were studied by atomic force microscopy (NT-MDT Solver P47). The hardness of the samples was measured by nanoindentation method. The adhesion of coatings to the branches was determined by the shear on the tensile testing machine RPM-10MG4.

It has been determined that mechanical polishing of the p-type semiconductor branches based on $\mathrm{Bi}_{2} \mathrm{Te}_{3}-\mathrm{Sb}_{2} \mathrm{Te}_{3}$ solid solution results in surface hardening, and also increases the adhesion of the Mo-Ni switching barrier layers by a factor of 2 compared with the adhesion of Mo-Ni layers on the surface of untreated branches. Subsequent electrochemical polishing increases the adhesion of Mo-Ni layers by 1.3 times, and pulsed photon treatment by 1.4 times compared with mechanically polished branches.

It is shown that the energy effect of an PPT stimulates local recrystallization of the defective layer near the surface of semiconductor branches at a depth of 100-200 nm and increases the hardness of the near-surface layers of the $\mathrm{Bi}_{2} \mathrm{Te}_{3}-\mathrm{Sb}_{2} \mathrm{Te}_{3}$ solid solution by 1.2 times.
\end{abstract}

Keywords: thermoelectricity, bismuth telluride, surface modification, barrier layer, phase composition, hardness, adhesion.

DOI: https://doi.org/10.17308/kcmf.2018.20/629 


\section{ACKNOWLEDGEMENTS}

The work was performed using the scientific equipment of the Center for collective use of them. prof. Yu.M. Borisov, Voronezh State University, Central Chernozem Collective Center for Analysis of the Structure, Elemental and Chemical Composition of Materials of the Voronezh State Technical University and with financial support from the Ministry of Education and Science of the Russian Federation in the framework of the Russian Federation Government Resolution of April 9, 2010 No. 218 (Contract No. 03. G25.31.0246).

\section{REFERENCES}

1. Osvensky V. B., Karataev V. V., Malkova N. V. Izvestiya Vysshikh Uchebnykh Zavedenii. Materialy Elektronnoi Tekhniki [Materials of Electronics Engineering], 2012, pp. 70-73. (in Russ.)

2. Xie W., Tang X., Yan Y., et al. Applied Physics Letters, 2009, vol. 94, no. 10, p. 102111. DOI: https://doi. org/10.1063/1.3097026

3. Brostow W., Datashvili T., Hagg Lobland H. E., et al. J. Mater. Res., 2012, vol. 27, no. 22, pp. 2931-2936. DOI: https://doi.org/10.1557/jmr.2012.335

4. Gromov D. G., Shtern Yu. I., Rogachev M. S., et al. Neorganicheskiye materialy [Inorganic Materials], 2016, vol. 52 no. 11, pp. 1132-1136. DOI: https://doi.org/10.1134/ S0020168516110030

5. Stern Yu. I., Shtern M. Yu., Sherchenkov A. A. Russ. Microelectron., 2012, vol. 41, no. 7, pp. 393-399. DOI: https://doi.org/10.1134/s1063739712070098

6. Yang N. Y. C., Morales, A. M. Morales Metallurgy, Thermal Stability, and Failure Mode of the Commercial Bi-Te-based Thermoelectric Modules. Sandia National Laboratories Albuquerque, New Mexico 87185 and Livermore, California 94550, 2009, p. 60. DOI: https://doi. org/10.2172/957291
7. Shtern, Y. I., Mironov R. E., Shtern M. Y., Sherchenkov A. A., Rogachev M. S. // Acta Physica Polonica A, 2016, vol. 129, no. 4, pp. 785-787. DOI: https://doi.org/10.12693/ aphyspola.129.785

8. Feng H.-P., Yu B., Chen Sh., et al. Electrochimica Acta, 2011, vol. 56, pp. 3079-3084. DOI: https://doi. org/10.1016/j.electacta.2010.12.008

9. Simkin A. V., Biryukov A. V., Repnikov N. I., Ivanov O. N. Journal of Thermoelectricity, 2012, no. 2, pp. 70 75.

10. Marchenko O. V., Kashin A. P., Lozbin V. I. Metody rascheta termoelektricheskikh generatorov [Methods for calculating thermoelectric generators]. Siberian Publishing Company "Nauka" RAS, 1995, p. 222. (in Russ.)

11. Belonogov Ye. K., Dybov V. A., Kostyuchenko A. V. Vestnik VGTU, 2017, vol. 13, no. 6, pp. 110-116. (in Russ.)

12. Belonogov Ye. K., Dybov V.A., Kostyuchenko A. V., et al. Condensed Matter and Interphases, 2017, vol. 19, no. 4, pp. 479-488. DOI: https://doi.org/10.17308/ kcmf.2017.19/226 (in Russ.)

13. Tewari K. C., Gandotra V. K., Padmavati M. V. G., Singh A., Vedeshwar A. G. Materials Chemistry and Physics, 2001, vol. 72, pp. 72-76. DOI: https://doi.org/10.1016/ s0254-0584(01)00312-1

14. Powder Diffraction File. Alphabetical Index Inorganic Compounds. JCPDS, Pennsylvania 19081, U.S.A., 1977, p. 17.

15. Goltsman B. M., Kudinov V. A., Smirnov I. A. Semiconductor Thermoelectric Materials Based on Bi, Te ${ }_{3}$. Nauka Publ., 1972. 161 p. (in Russ.)

16. Tasi C.-H., Tseng Y.-C., Jian S.-R., et al. Journal of Alloys and Compounds, 2015, vol. 619, pp. 834-838. DOI: https://doi.org/10.1016/j.jallcom.2014.09.028

17. Santamarha J. A., Alkorta J., Sevillano J. G. J. Mater. Res., 2015, vol. 30, no. 17, pp. 2593-2604. DOI: https://doi.org/10.1557/jmr.2015.170
Белоногов Евгений Константинович - д. ф.-м. н., профессор, Воронежский государственный университет, Воронеж, Россия; тел.: +7 (473) 2467633 , e-mail: ekbelonogov@mail.ru

Дьгов Владислав Анатольевич - м. н. с., Воронежский государственный технический университет, Воронеж, Россия; тел.: +7 (473) 2467633, e-mail: dybovvlad@gmail.com

Костюченко Александр Викторович - к. ф.м. н, заведующий лабораторией, Воронежский государственный технический университет, Воронеж, Россия; тел.: +7 (473) 2467633, e-mail: av-kostuchenko@mail.ru
Evgenii K. Belonogov - Dr. Sci. (Phys.-Math), Full Professor, Voronezh State University, Voronezh, Russia; tel.: +7 (473) 2467633, e-mail: ekbelonogov@mail.ru

Vladislav A. Dybov - Junior Researcher, Voronezh State Technical University, Voronezh, Russia; tel.: +7 (473) 2467633, e-mail: dybovvlad@gmail.com

Aleksandr V. Kostyuchenko - Cand. Sci. (Phys.Math), Head of Laboratory, Voronezh State Technical University, Voronezh, Russia; tel.: +7 (473) 2467633, e-mail: av-kostuchenko@mail.ru 
Кущзев Сергей Борисович - д. ф.-м. н., професcop, в. н. с., Воронежский государственный технический университет, Воронеж, Россия; тел.: +7 (473) 2467633, e-mail: kushev_sb@mail.ru

Сериков Дмитрий Владимирович - м. н. с., Воронежский государственный технический университет, Воронеж, Россия; тел.: +7 (473) 2467633, еmail: dmitriy.tut@mail.ru

Солдатенко Сергей Анатольевич - к. ф.-м. н., доцент, Воронежский государственный технический университет Воронеж, Россия; тел.: +7 (473) 2467633, e-mail: cossack408@mail.ru

Федорова Елена Николаевна - м. н. с., Воронежский государственный технический университет, Воронеж, Россия; тел.: +7 (473) 2467633, e-mail: en-fedorova@mail.ru

Погорелова Мария Александровна - магистр, Воронежский государственный технический университет, Воронеж, Россия; тел.: +7 (473) 2467633, e-mail: mashapogorelova.97@mail.ru

Росляков Артем Олегович - магистр, Воронежский государственный технический университет, Воронеж, Россия; тел.: +7 (473) 2467633, e-mail: rap36@imbox.ru
Sergei B. Kuschev - Dr. Sci. (Phys.-Math), Full Professor, Voronezh State Technical University, Voronezh, Russia; tel.: +7 (473) 2467633, e-mail: kushev_sb@mail.ru

Dmitrii V. Serikov - Junior Researcher, Voronezh State Technical University, Voronezh, Russia; tel.: +7 (473) 2467633, e-mail: dmitriy.tut@mail.ru

Sergei A. Soldatenko - Cand. Sci. (Phys.-Math), Assistant Professor, Voronezh State Technical University, Voronezh, Russia; tel. +7 (473) 2467633, e-mail: cossack408@mail.ru

Elena N. Fedorova - Junior Researcher, Voronezh State Technical University, Voronezh, Russia; tel.: +7 (473) 2467633, e-mail: en-fedorova@mail.ru

Maria A. Pogorelova - Master's Degree, Voronezh State Technical University, Voronezh, Russia; tel.: +7 (473) 2467633, e-mail: mashapogorelova.97@mail.ru

Artem O. Roslyakov - Master's Degree, Voronezh State Technical University, Voronezh, Russian; tel.: +7 (473) 2467633, e-mail: rap36@imbox.ru 